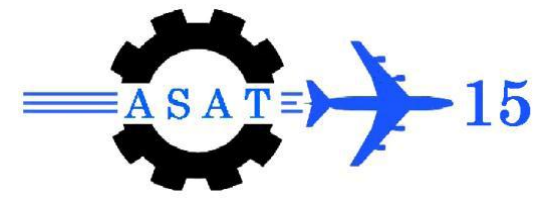

\title{
Numerical Evaluation of Composite Plates Performance under the Effect of Underwater Explosion
}

\author{
F. Elsayed*, N. M. Nagy ${ }^{\dagger}$, Tong Lili*
}

\begin{abstract}
This paper examines the performance of composite plates with PVC foam cores and T700/epoxy composites face sheets, and steel plate have the same areal mass when subjected to Underwater Explosion (UNDEX). The objective of this study is to evaluate the dynamic response of those plates. A non-linear dynamic numerical analysis of the underwater explosion phenomena is performed using the ABAQUS/Explicit finite element code, which provides an important analysis tool that can help engineers and designers to design and construct better structures to resist shock loads. The temporal evolutions of plate deflection and central deflection histories were obtained. Further investigations have been performed to study the behavior of failure. The results indicate that the behavior of composite plate with PVC foam core to resist shock loads resulting from an UNDEX is better than steel plate, and the core thickness has a great effect on the plate`s response. The obtained numerical results can help to suggest design guidelines of floating structures to enhance resistance to underwater shock damage, since explosive tests are costly and dangerous.
\end{abstract}

Keywords: Underwater explosion, composite plates, ABAQUS/Explicit, PVC foam cores,

\section{Introduction}

Sandwich panels based on two relatively stiff face sheets separated by a foam core are commonplace in the marine industry for example in surfboard and yacht construction. Lightweight sandwich materials are attractive options for the transport industry which is seeking to improve fuel economy and speed whilst reducing harmful emissions. Also when a naval ship is attacked by an underwater explosion (UNDEX), the ship can be severely damaged by shock waves and gas bubble pulse, predicting the shock response of ships to noncontact UNDEX from underwater weapon is of great importance for the warhead design of underwater weapon as well as the naval ship design for defending underwater shock. The design and analysis of structure subjected to UNDEX requires a detailed understanding of explosion phenomena and the dynamic response of various structural elements [1]. The most important way to reduce the damage due to UNDEX loading is to provide sufficient standoff distance between the structure and explosion source and decrease the effect of the blast wave so that the structure not highly damaged. To accomplish these objectives, it is necessary to do various scenarios to evaluate the behavior of the ship structure to blast loading. These scenarios should include studying such aspects (explosive magnitude, distance from source of explosion, structure scantling, complex fluid-structure interaction phenomena, structure geometry, etc.).

\footnotetext{
College of Aerospace and Civil Engineering, Harbin Engineering University, Harbin 150001, China.

† Egyptian Armed Forces, Egypt, nabilmnagy@yahoo.com 
Z. Wei [2] studied the response of a sandwich panel with a multilayered pyramidal lattice core subjected to underwater blast. It has been investigated by a combination of experimental tests. The tests affirmed that the transmitted pressure and impulse are significantly reduced when a solid cylinder is replaced by the sandwich panel.

Y. Chi et al[3] investigated the behavior of circular sandwich panels with Aluminium honeycomb cores subjected to air blast loading. It was observed that the panels exhibited permanent face plate deflection and tearing, and the honeycomb core exhibited crushing and densification. It was found that increasing the core thickness delayed the onset of core densification and decreased back plate deflection.

Fleck and Deshpande[4] developed analytical formulae to characterize the structural response of clamped metallic sandwich beams subjected to uniformly distributed air and water blasting loads. The study reviewed and compared the blast performance of a monolithic plate and various core topologies.

Yuen et al. [5] presented an overview on sandwich panels subjected to blast loading. A variety of core topologies were investigated in these studies and the results have shown that metal sandwich panels have the potential to perform better than monolithic plates under certain impact and blast situations.

H.E. Johnson[6] numerically modeled woven vinyl-ester composite plates. Delamination is modeled with a mixed-mode traction separation law using cohesive elements and the results are compared with full-scale tests. It is observed that modeling 3D damage at the ply level and delamination reduces the contact force by up to $42 \%$ compared tothe no-damage model but generally increases the contact time and out-of-plane displacement compared to the experiment.

F. Latourte[7] examined the performance of composite panels when subjected to under- water impulsive loads. He found that for composite sandwich panels, the relationship between maximum center deflections versus applied impulse per areal mass was found to be approximately bilinear but with a higher slope and negative intercept.

LeBlanc [8] studied the dynamic responses of composite panels to underwater explosive loading both experimentally and computationally. The displacement and velocity data for the center point and a point halfway between the center and boundary are correlated to the computational models by utilizing the Russell error. The Russell error value for the deflection correlation at these two points was excellent. The velocity correlation at the point halfway between the center and the boundary is also excellent, while the center point velocity has acceptable correlation.

C.Y. Jen [9] used the ABAQUS, finite element software to simulate and analyze the transient dynamic response of a midget submersible vehicle pressure hull that experiences loading by an acoustic pressure shock wave resulting from an underwater explosion (UNDEX). It was found that the shock wave caused by the detonation of a $18.3 \mathrm{~kg}$ TNT charge is detonated $7.62 \mathrm{~m}$ away from the side of the amidships of the hull, made the pressure hull yield, but not collapse.

A. Forghani [10] studied the modeling of damage development in blast loaded composite laminates to blast loads. The numerical test-bed for the simulations is the explicit finite element code, LS-DYNA. It was shown that the tie-break interface option in LS-DYNA can be used successfully in simulating cohesive cracks. The sudden release of energy from underwater explosions of a conventional high-explosive or nuclear weapon generates a shockwave and forms a superheated, highly compressed gas bubble in the surrounding water of the total energy released from a 1500-lb TNT underwater explosion. Approximately 53\% goes into the shockwave and $47 \%$ goes into bubble pulsation. Most cases demonstrate that the damage done to marine structures, such as the surface of ships and submarines, occurs early 
and is due to the primary shockwaves. This investigation only considers the effects of the shockwaves as demonstrated in [11and12].

Langdon [13]studied an experimental and numerical investigation into the response of sandwich panels to localized blast loading. These sandwich panels contained PVC foam cores and glass fiber reinforced vinyl ester face sheets, and an equivalent mass glass fiber reinforced vinyl ester panels. The analysis reveals the reasons why the only composite panels perform better than the sandwich panels with PVC foam core due to the lower transverse stiffness of the individual components of the sandwich panel.

Tekalur [14] studied the tensile, compressive and shear properties of composites with vinyl ester matrices under quasi-static and dynamic rates of loading. They also reported results from some limited shock and blast tests on the same materials, and observed that fiber breakage and delimitation are common damage mechanisms.

\section{Empirical Formula for Shock Wave and Bubble Pulse}

Non-contact underwater explosion is the major source of threat to ships and submarines. Noncontact underwater explosion to the responses and damages of submerged structures is divided into two categories: near-field explosion and far-field explosion depending on the distance between the explosive charge and the target (standoff distance) as demonstrated in [9].

Figure (1) shows the different events occurring during the UNDEX in a pressure against time history plot as stated in [15]. The under pressure condition as shown in Figure (1) is caused by the back flow of the water toward the explosive due to the contraction of the bubble. The reflection of the shock wave off the bottom of the ocean is a compression wave that adds additional load to the structure. The reflection of the shock wave from free ocean surface causes a reduction in the pressure produced by the shock wave as demonstrated in[10 and 16].

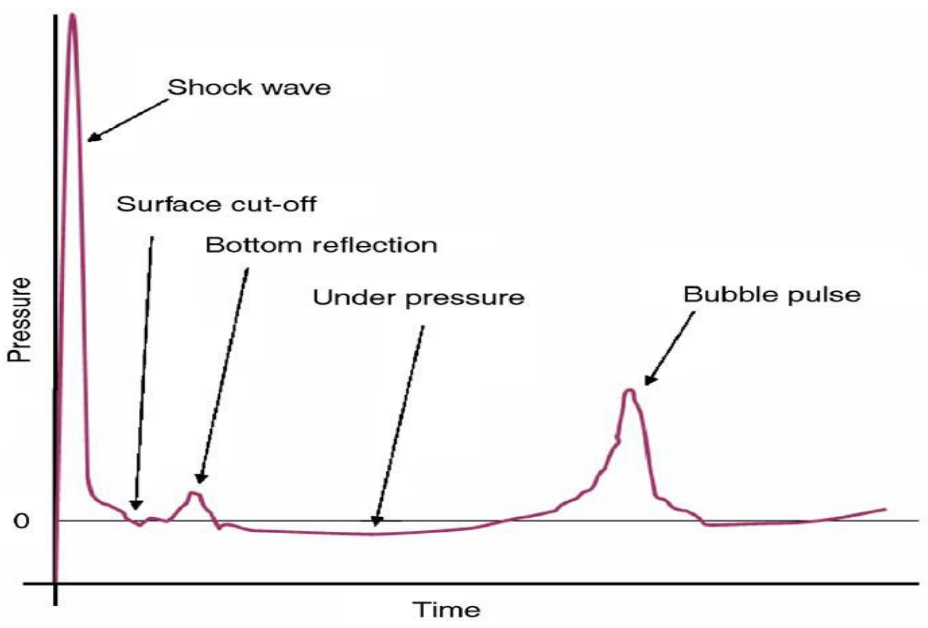

Fig. 1. Phenomenon of the UNDEX: shock wave and high pressure bubble appear after explosion. [18]

In the present research, the incident wave is the shock wave produced by the UNDEX charge. The scattered wave is the acoustic field generated by the interaction of the incident wave and the submerged structure. The initial shock wave modeled as a spherical incident shock wave applied as a transient load active on both the acoustic and structural meshes at their common surfaces (the wetted interface). The distribution of this shock wave onto the plate is obtained using the incident pressure wave equations as demonstrated in [10 and 17].Cole [11] illustrated this phenomenon and approximated the associated blast pressure decay as a 
function of charge mass and stand-off distance and proposed an empirical equation for the pressure profile as follows:

$P(t)=P_{\max } e^{-\left(\frac{t-t_{1}}{\theta}\right)} t \geq t_{1}$

where $P_{\max }(p s i)$ is The peak pressure of an exponentially decaying for spherical charges in a free field underwater explosion shock wave generated at a standoff distance $R(f t)$ that is greater than 10 times the radius of the charge of an equivalent TNT weight $W(I b)$ is given as

$P_{\max }=K_{1}\left(\frac{W^{\frac{1}{3}}}{R}\right)^{A_{1}}(p s i)$

The decay constant, $\theta$, the bubble oscillation period Tand the maximum radius of the first bubble of explosive gas $R_{\max }$ and the energy per unit volume $E$ can be expressed as follows [19]

$\theta=K_{2} W^{1 / 3}\left(\frac{W^{\frac{1}{3}}}{R}\right)^{A_{2}} \quad($ msec $)$

$T=K_{5} \frac{W^{\frac{1}{3}}}{(D+33)^{5 / 6}}(\mathrm{sec})$

$R_{\max }=K_{6}\left(\frac{W}{(D+33)}\right)^{1 / 3}(f t)$

$E=K_{4} W^{\frac{1}{3}}\left(\frac{W^{\frac{1}{3}}}{(R)}\right)^{A_{4}}\left(I b-i n / i n^{3}\right)$

where; $K_{1}, K_{2} K_{4}, K_{5}, K_{6}, A_{1}$, and $A_{1}, A_{2}, A_{4}$ are constants that depend on explosive charge type when different explosives are used. These input constants are as stated in Table 1 , and $W$ is the weight of the explosive charge in $(I b)$ and $R$ is the distance between the explosive charge and target in $(f t)$.

For an air backed plate of mass per unit area $(m)$ subjected to an incident plane shockwave $P_{i}(t)$, a reflection wave of pressure $P_{r}(t)$, leaves the plate, which is moving at velocity $v_{p}(t)$. It can be expressed by using Newton's second law of motion.

$m \cdot \frac{d v_{p}}{d t}=P_{i}+P_{r}$

The fluid particle velocities behind the incident and reflected shockwave are $v_{i}(t)$ and $v_{r}(t)$ respectively, thus the velocity of the plate becomes

$v_{p}(t)=v_{i}(t)-v_{r}(t)$

The incidence and reflective shockwave pressures are $P_{i}=\rho_{f} c v_{i}$ and $P_{r}(t)=$ $\rho_{f} c v_{r}$ respectively, where $\rho_{f}$ is fluid density and $C$ is the sound velocity. By substituting the pressure into Eq. (7) and solving with Eq. (1), $P_{r}(t)$ becomes:

$P_{r}(t)=P_{i}(t)-\rho_{f} c v_{p}=P_{\max } e^{-\left(\frac{t-t_{1}}{\theta}\right)}-\rho_{f} c v_{p}$

Eq. (7) can then be rewritten as:

$m \cdot \frac{d v_{p}}{d t}+\rho_{f} c v_{p}=2 P_{\max } e^{-\left(\frac{t-t_{1}}{\theta}\right)}$ 
Differentiating Eq. (10) yields the following expression for plate velocity, where $\psi=\frac{\rho_{f C \theta}}{m}$ and $t>0$.The total pressure on the plate is:

$P_{t}(t)=2 P_{i}(t)-\rho_{f} c v_{p}=\frac{2 P_{\max }}{1-\psi}\left[e^{-\left(\frac{t-t_{1}}{\theta}\right)}-\psi^{e^{\frac{-\psi\left(t-t_{1}\right)}{\theta}}}\right]$

Table 1: Shock wave parameters for various explosive charge [19]

\begin{tabular}{c|c|c|c|c|c}
\hline \hline \multirow{2}{*}{ Constants } & \multicolumn{4}{|c}{ Explosive material Type } \\
\cline { 2 - 6 } & & HBX-1 & TNT & PETN & Nuclear \\
\hline \hline \multirow{2}{*}{$P_{\max }$} & $K_{1}$ & 22347 & 22505 & 24589 & 4380000 \\
\cline { 2 - 6 } & $A_{1}$ & 1.144 & 1.180 & 1.194 & 1.18 \\
\hline \multirow{2}{*}{ Decay constant } & $K_{2}$ & 0.056 & 0.058 & 0.052 & 2.274 \\
\cline { 2 - 6 } & $A_{2}$ & -0.247 & -0.185 & -0.257 & -0.22 \\
\hline Bubble period & $K_{5}$ & 4.761 & 4.268 & 4.339 & 515 \\
\hline Bubble radius & $K_{6}$ & 14.14 & 12.67 & 12.88 & 1500 \\
\hline \multirow{2}{*}{ Energy } & $K_{4}$ & 3086.5 & 3.0349 & 3.1352 & $3.313 \mathrm{E} 8$ \\
\cline { 2 - 6 } & $A_{4}$ & 2.039 & 2.155 & 2.094 & 2.04 \\
\hline \hline
\end{tabular}

\section{Geometry of the Plates}

In this investigation seven models are considered.Six sandwich panels and one steel panel are considered. Model 1 represents steel panel $20 \mathrm{~mm}$ thick and models 2, 3, 4, 5 and 6 represent the sandwich panels with deferent core thickness $(30,20,15,10$, and 5) $\mathrm{cm}$ respectively. All of these models have the same areal mass except model 7 has the half areal mass. All the panels are $3000 \times 3000 \mathrm{~mm}^{2}$.

\section{Finite Element Modeling}

In this paper, the non-linear finite element program ABAQUS/Explicit is used to undertake a three-dimensional (3D) analysis of the problem. The results have been visualized using ABAQUS/CAE

\subsection{Model geometry}

ABAQUS/Explicit offers an element library for a wide range of geometric models. In the present study, the fourth noded shell element (S4R) with reduced integration and hourglass control was used to model the geometry of the plates. The models consist of grids of shell elements of size $0.075 \mathrm{~m}$. The discritization used for the model is as shown in the Figure (2). The fluid region of the model is represented by an assemblage of 4-node acoustic tetrahedral elements (AC3D4) as shown in Figure (3). The outer boundary of the external fluid is represented by half cylindrical surface as shown in Figure(4).

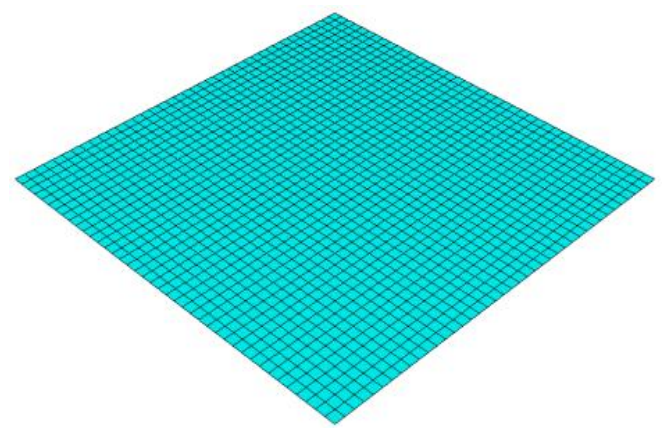

a) Finite Element Model ( structure model)

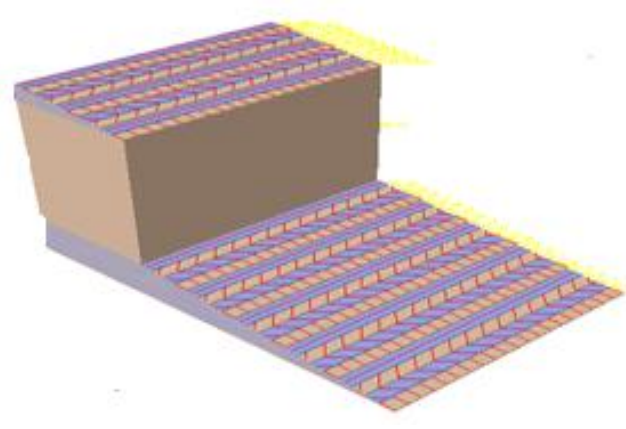

b) Cross section in the composite panel

Fig. 2. Geometrical configurations of panels 


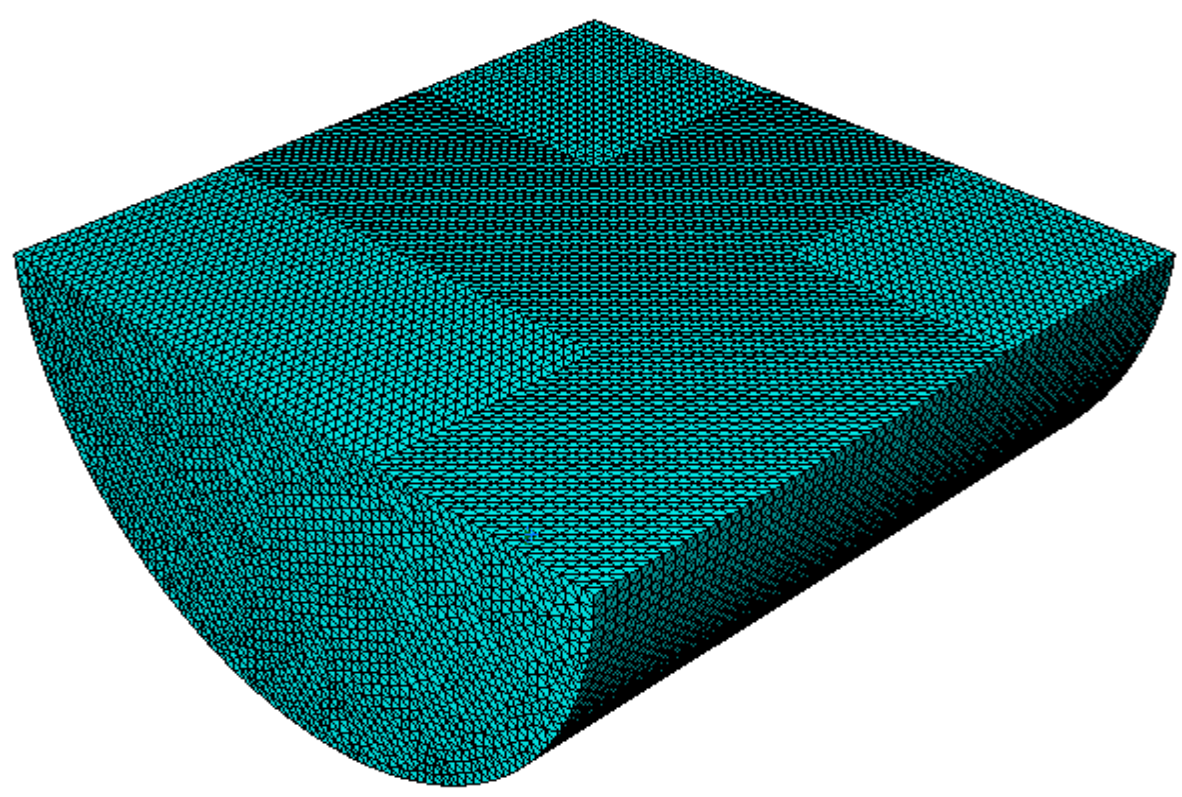

Fig. 3. Finite Element Model ( Fluid region )

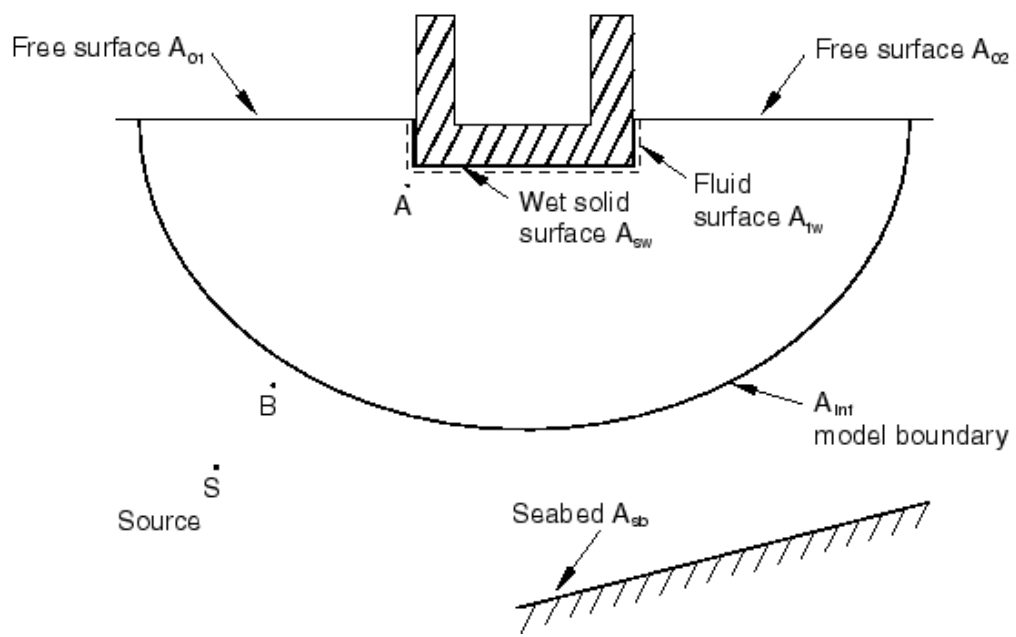

Fig. 4. The outer and free surface used in fluid model [22]

\subsection{Boundary conditions and fluid-structure coupling}

The panel on the ship's frame is typically stiffened by beams or stringers; thus, the panel can be divided into many small panels. The restraining moment of the borders of these panels is the torsional rigidity of a girder of stringer. During analysis, fully clamped boundary conditions are imposed on the four sides of the panels. The boundaries of the fluid may cause shockwave refraction or reflection, resulting in its superposition or cancellation by the incident wave [20].To prevent this phenomenon, the boundary condition of the fluid element is set as a non-reflective boundary during analysis except the free surface where zero pressure boundary condition was applied to it as shown in Figure(4). 
Restated all pressure flows out of this boundary and will not cause reflection, which typically affects the outcome of the analytical range. The acoustic-structural interaction between the wet surfaces of the plate and the acoustic interaction surfaces (the wetted interface) was implemented by use of a surface-based "tie" constraint, the location of the charge and the stand-off point defined as reference point, prior to the interaction, the INCIDENT WAVE PROPERTY option is used to specify the incident wave as spherical. The data lines for this option are used to define the location of the standoff point and source point in terms of global Cartesian coordinates. The INCIDENT WAVE option is used to activate incident wave loading, the load is applied on both the structure and the fluid at their common interface which is similar to a distributed load, and more details are available in reference [21, 22].

\subsection{Material properties}

The steel plate is made of mild steel. The numerical model uses the constitutive law for elastic/plastic materials to model the stiffened panel. Isotropic hardening rules are adopted in the hardening model. The parameters of steel used in the numerical model are as follows:

The Poisson ratio is 0.3 and Mass density is $7800 \mathrm{~kg} / \mathrm{m}^{3}$. The initial yield stress is $300 \mathrm{MPa}$, and the yield stress increases to $400 \mathrm{MPa}$ at a plastic strain of $35 \%$. Table (2) shows the plastic material properties for steel used in this study [26].

When the material sustains momentary dynamic loading, the effect of the strain rate cause the material's dynamic strength to exceed the strength during a static experiment; thus, the effect of strain rate must be considered during the analysis to match actual situations. As recommended by Jones [21] this study adopts the Cowper-Symonds strain rate mode as follows:

$\sigma_{d y}=\sigma_{y}\left[1+|\dot{\epsilon} / D|^{1 / q}\right]$

where $\sigma_{d y}$ is the material's dynamic yielding stress, $\sigma_{y}$ is the material's yielding stress, $\dot{\epsilon}$ is strain rate, and $D$ and $q$ are material parameters, whose values are normally $D=40 s^{-1}$ and $q=$ 5 for steel.

The sandwich plate consists of a foam core surrounded by fiber-reinforced laminates. T700/3234 epoxy unidirectional composite is chosen to model the laminates and Divinycell $\mathrm{H}$ grade polyvinyl chloride (PVC) closed-cell foams [24] are used to model the core material sandwich plate. The material properties of T700/3234 epoxy and foam core material are given in Table 3 [24] and the strength parameters for T700/ epoxy composites are shown in Table 4[25].

The fluid region of the model is represented by the acoustic fluid domain. Its properties are the bulk modulus and density. In this numerical investigation, commonly accepted values for the sea water were stated in [21]. The bulk modulus is $2140.4 \mathrm{MPa}$ and the density of the seawater is $1000 \mathrm{~kg} / \mathrm{m}^{3}$.

\section{Results and Discussions}

This study is based on the plate's performance improvement ratio $I_{R}$ (an indicator to measure the enhancement in displacement) for different effective studied parameters. The core thickness is one of the most important parameters play an effective influence on improving the plate's performance. 


\subsection{Effect of core thickness on mid-point displacement}

The inclusion of core decreases significantly the mid-point displacement. As shown in Figure (6-a) the mid-point displacement for model 1which represent steel plate is $99.69 \mathrm{~mm}$, while for models 2, 3, 4, 5 and 6which represent composite plate with core thickness 30, 20, 15, 10 and $5 \mathrm{~cm}$ and have the same weight as steel plate is $41.69 \mathrm{~mm}, 57.11 \mathrm{~mm}, 57.7 \mathrm{~mm}, 64.53$ $\mathrm{mm}$, and $68.44 \mathrm{~mm}$ respectively and for model 7 which represent composite plate with core thickness $30 \mathrm{~cm}$ and its areal mass half the areal mass of the steel plate is $59.1 \mathrm{~mm}$. Therefore, the core thickness has an important influence on the response of the plates. Figure (6-b) shows the maximum displacement at the center of the plates and the Improvement Ratio $\left(I_{R}\right)$ for all models. It can be noted that the best $I_{R}$ value is $58.20 \%$ for model 2 and the lowest $I_{R}$ is $31.34 \%$ for model 6 which indicate that as the core thickness increase, the $I_{R}$ increase.

Table 2: Plastic material properties for steel [26]

\begin{tabular}{c|c}
\hline \hline True Stress (Pa) & True Plastic Strain \\
\hline \hline $300 \times 10^{6}$ & 0.000 \\
\hline $350 \times 10^{6}$ & 0.025 \\
\hline $375 \times 10^{6}$ & 0.100 \\
\hline $394 \times 10^{6}$ & 0.200 \\
\hline $400 \times 10^{6}$ & 0.350 \\
\hline \hline
\end{tabular}

Table 3: Material properties of the sandwich components [24]

\begin{tabular}{l|c}
\hline \hline \multicolumn{1}{c|}{ Material } & Material constants \\
\hline \hline T700/epoxy composites & $\mathrm{E}_{11}=132 \mathrm{GPa}, \mathrm{E}_{22}=10.3 \mathrm{GPa}, \mathrm{E}_{33}=10.3 \mathrm{GPa}, \mathrm{G}_{12}=6.5 \mathrm{GPa}$, \\
& $\mathrm{G}_{13}=6.5 \mathrm{GPa}, \mathrm{G}_{23}=3.91 \mathrm{GPa}, v_{12}=0.25, v_{13}=0.25, v_{23}=0.38$, \\
& $\rho=1570 \mathrm{~kg} / \mathrm{m}^{3}$ \\
\hline PVC foam H100 & $\mathrm{E}=160 \mathrm{MPA}, \mathrm{G}=50 \mathrm{MPA}, \mathrm{v}_{23}=0.3, \rho=100 \mathrm{~kg} / \mathrm{m}^{3}$ \\
\hline \hline
\end{tabular}

Table 4: Strength parameters for T700/ epoxy composites [25]

\begin{tabular}{c|c|c|c|c}
\hline \hline $\mathrm{X}_{\mathrm{t}}(\mathrm{Mpa})$ & $\mathrm{X}_{\mathrm{c}}(\mathrm{Mpa})$ & $\mathrm{Y}_{\mathrm{t}}(\mathrm{Mpa})$ & $\mathrm{Y}_{\mathrm{C}}(\mathrm{Mpa})$ & $\mathrm{S}(\mathrm{Mpa})$ \\
\hline 2150 & 2150 & 298 & 298 & 778 \\
\hline \hline
\end{tabular}

\subsection{Effect of core thickness on mid-point displacement}

The inclusion of core decreases the mid-point displacement significantly. As shown in Figure (6-a) the mid-point displacement for model 1 which represents steel plate is $99.69 \mathrm{~mm}$, while for models 2, 3, 4,5and 6which represent composite plate with core thickness 30,20,15,10, and $5 \mathrm{~cm}$ and have the same weight as steel plate is $41.69 \mathrm{~mm}, 57.11 \mathrm{~mm}, 57.7 \mathrm{~mm}, 64.53 \mathrm{~mm}$, and $68.44 \mathrm{~mm}$ respectively and for model 7 which represent composite plate with core thickness $30 \mathrm{~cm}$ and its areal mass half the areal mass of the steel plate is $59.1 \mathrm{~mm}$. Therefore, the core thickness has an important influence on the response of the plates. Figure (6-b) shows that the Improvement Ratio $\left(I_{R}\right)$ for all models. It can be noted that the best $I_{R}$ is $58.20 \%$ for model 2 and the lowest $I_{R}$ is $31.34 \%$ for model 6 which indicate that as the core thickness increase, the $I_{R}$ increase. 


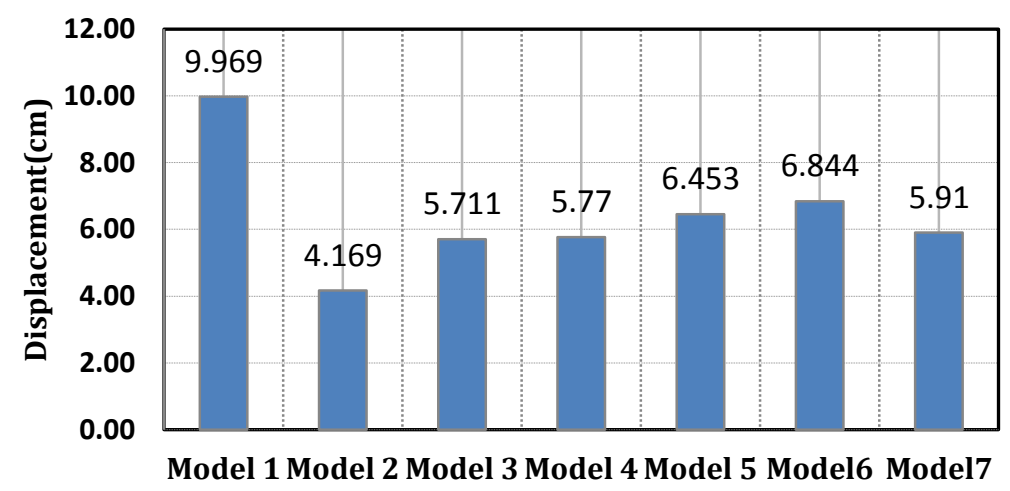

(a) Maximum displacement at the center of the plates

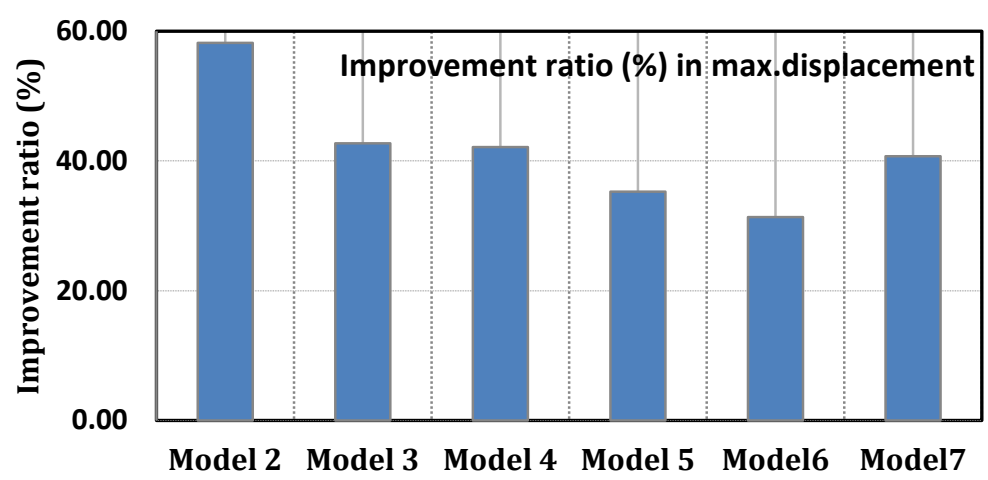

(b) Improvement ratio

Fig. 6. Max displacement and Improvement ratio for all models

The maximum displacement of the center point of all plate's models is monitored with time in order to evaluate the performance of the plates under the effect of shock loads. Figure (7) shows the maximum displacement values at different time history $0.01 \mathrm{sec}, 0.015 \mathrm{sec}, 0.02$ $\mathrm{sec}$ and $0.025 \mathrm{sec}$ for the plates.

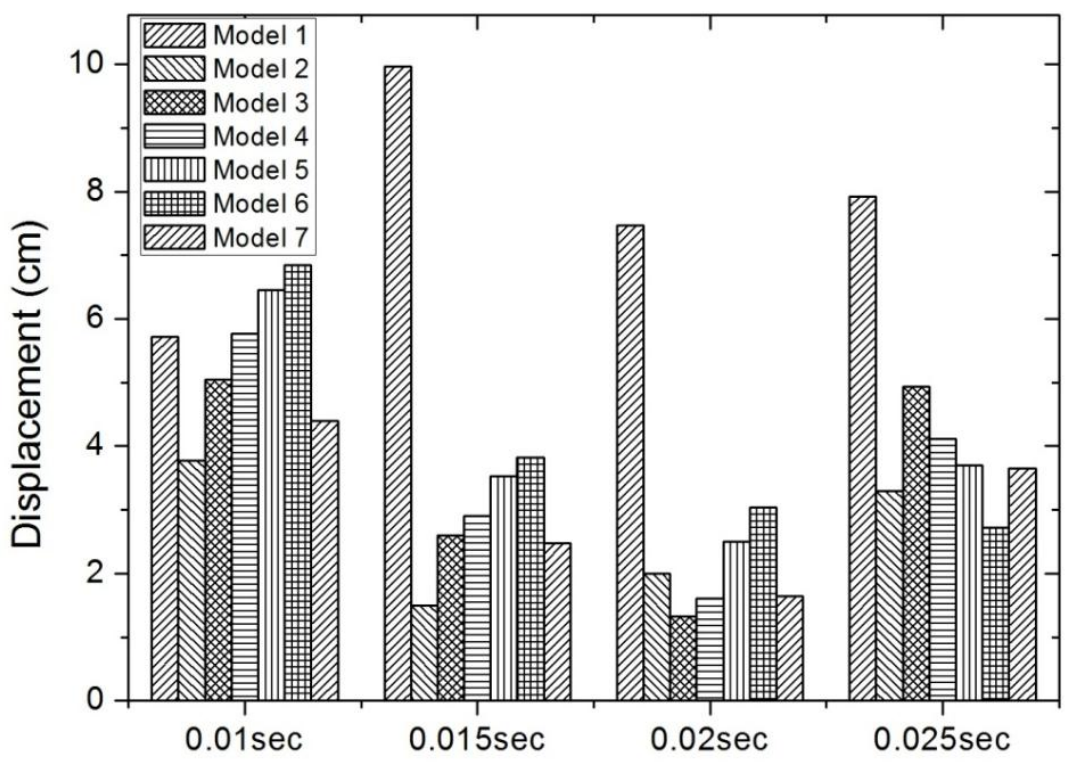

Fig. 7. Maximum displacement at the center of the plates 


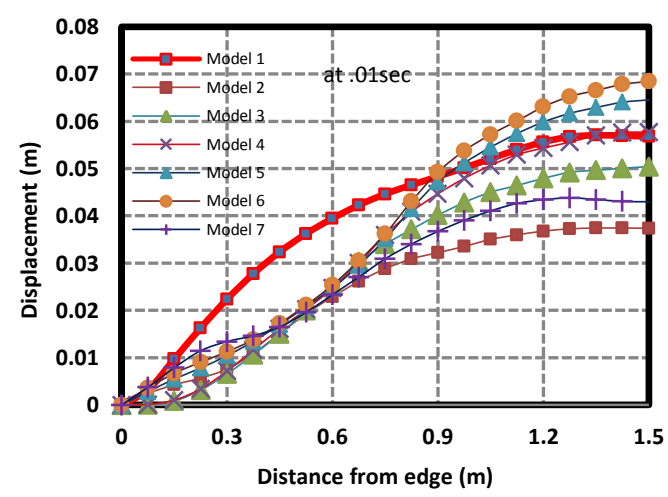

(a) at $10 \mathrm{~ms}$

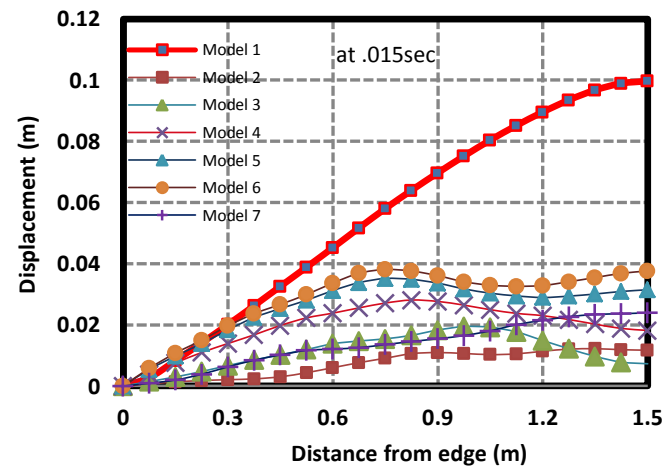

(c) at $15 \mathrm{~ms}$

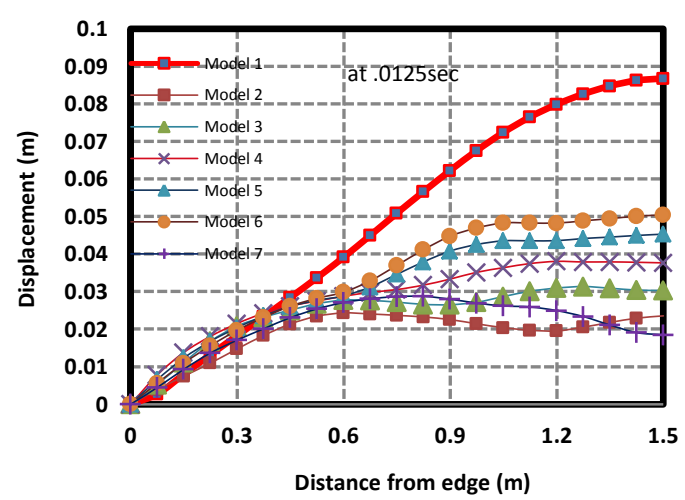

(b) at $12.5 \mathrm{~ms}$

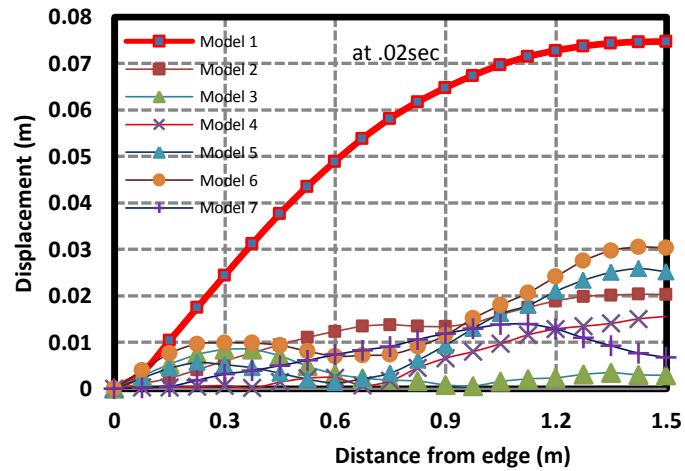

(d) at $20 \mathrm{~ms}$

Fig. 8. The transverse center-line deformation of plates

Figure (8) shows the transverse center-line deformation of all models. It can be noted that, the maximum deformation occurs at the center of the plates and reduced gradually towards the fixed boundaries. It can be seen from Figure (8.a), that model 1 has the maximum deformation until the distance equal $0.9 \mathrm{~m}$, and its rate increase towards the center of the plates. Model 6 has the maximum displacement from distance equal $0.9 \mathrm{~m}$ and increase gradually towards the center of the plate. It can be found that, Model 2 has the minimum displacement. The behavior of the transverse center-line deformation in case of steel plate is different from the behavior of composite plates.

Figures (8.b, c, and d) also show the transverse center-line deformation and it can be noted that model 1 has the maximum deformation and this deformation increase linear as the distance from the edge of the plate increase and reaches the maximum value at the center of the plate. 


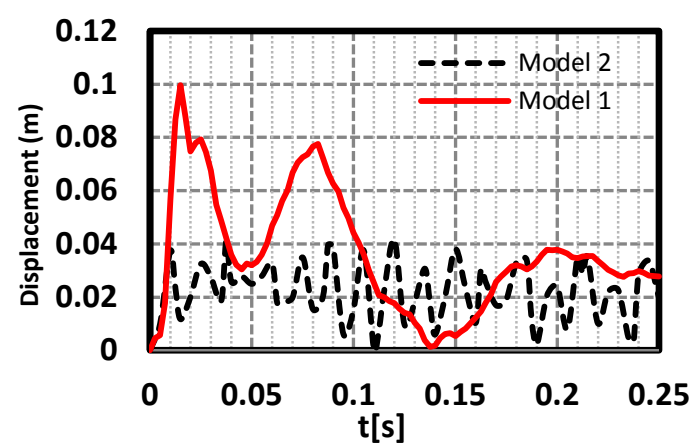

(a) Model 1 and Model 2

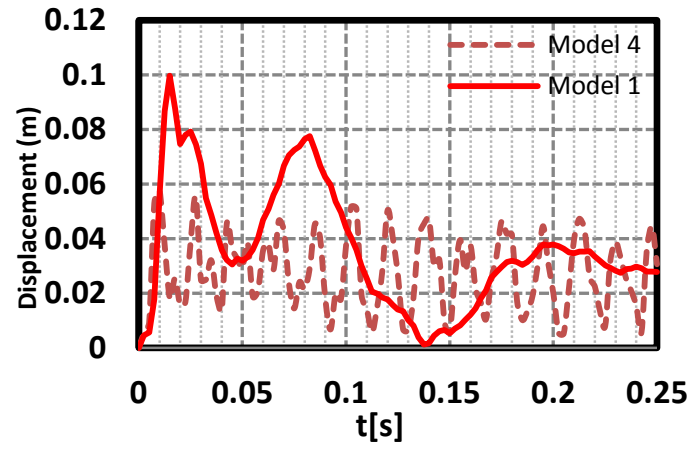

(c) Model 1 and Model 4

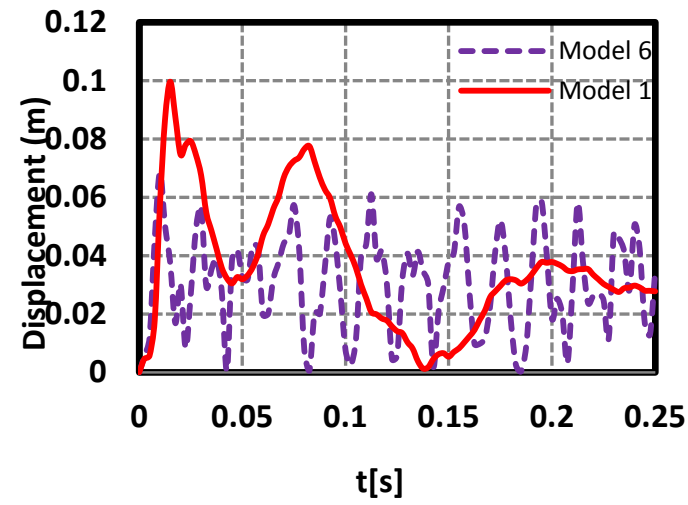

(e) Model 1 and Model 6

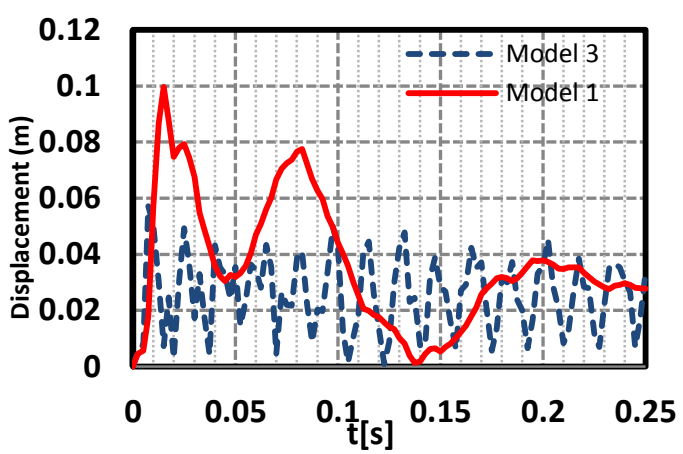

(b) Model 1 and Model 3

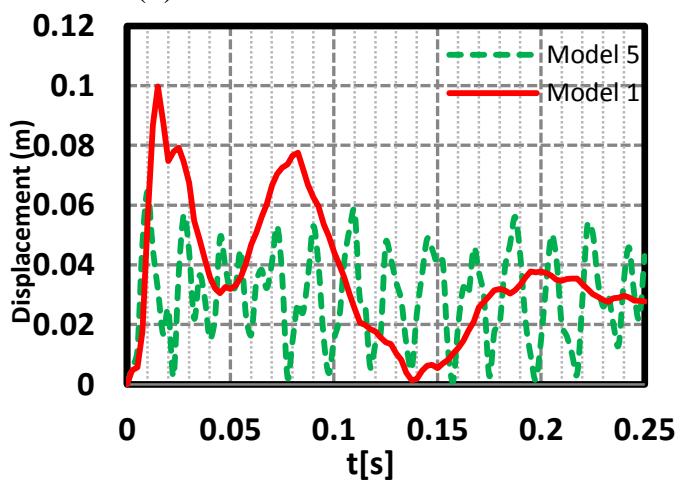

(d) Model 1 and Model 5

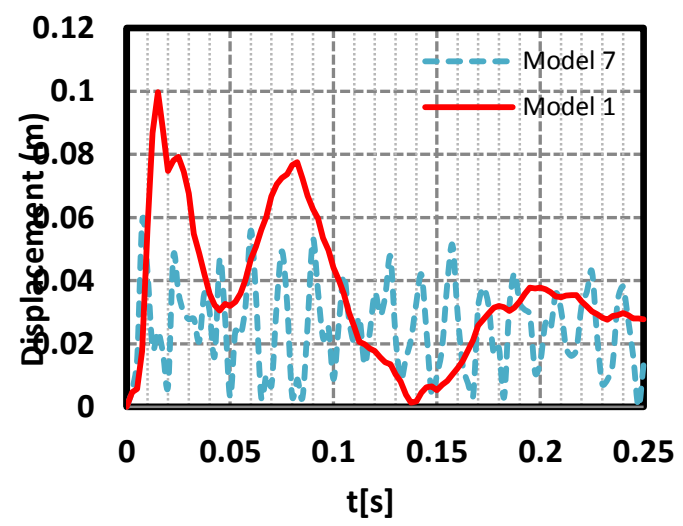

(f) Model 1 and Model 7

Fig. 9. Displacement in the central node with time

For better understanding of the different plate's response to the shock loading, the displacement histories of the central node for all models were presented in Figures (9).The displacements shown in Figures (9) are significantly enhanced as the core thickness increase. Figure (9-a) shows the values of maximum central displacement for model 1 and model 2.It can be noted that, in case of model 2 the maximum displacement is less than the maximum displacement in model 1 .

Fringe plots of thedisplacement also are shown in Figure (10), the maximum magnitude of the displacement occurs at centroids regions of the plates as the core thickness decrease the maximum displacement increase. It confirms that theproposal with maximum core thickness can help the structure to sustain shock loads resulting from an underwater explosion. 


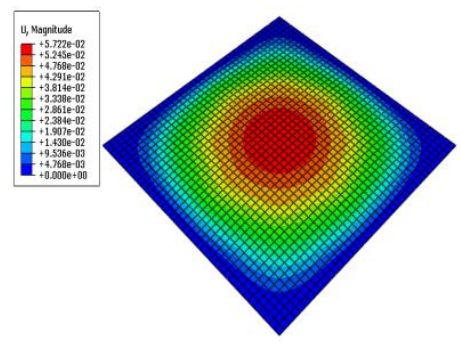

Model 1

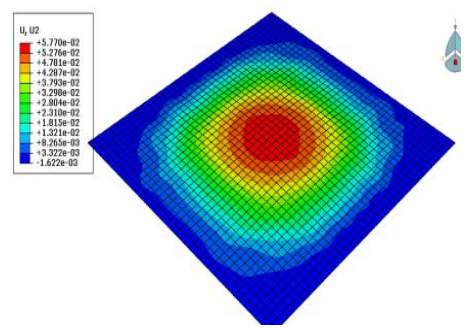

Model 4

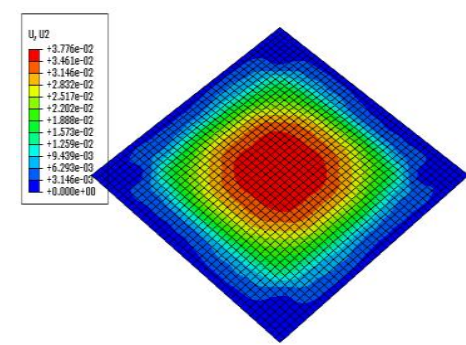

Model 2

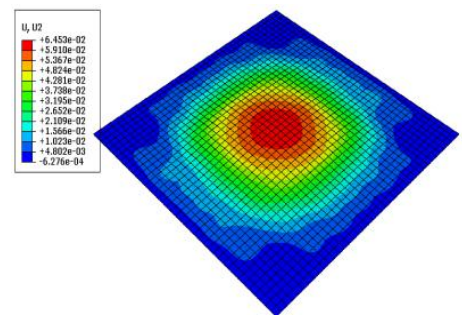

Model 5

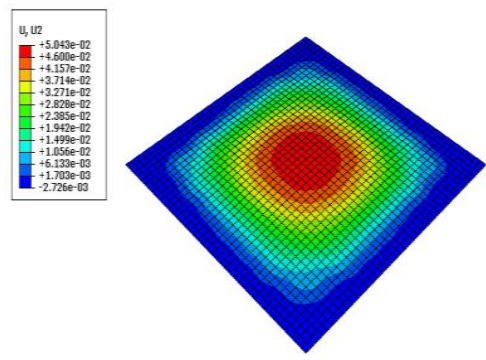

Model 3

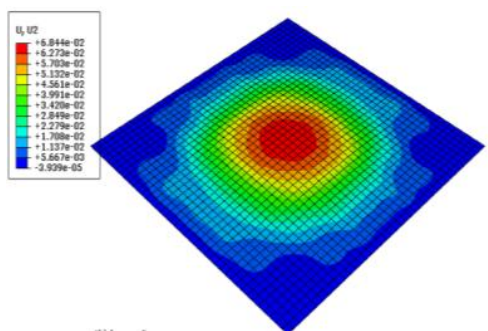

Model 6

Fig. 10. Displacement distribution for all models at 1E-2sec

\subsection{Tsai-Hill Failure}

The Tsai-Hill failure theory is derived from the von Mises distortional energy yield criterion for isotropic materials but is applied to anisotropic materials with the appropriate modifications. In this theory, failure is assumed to occur whenever the distortional yield energy equals or exceeds a certain value related to the strength of the lamina. In this theory, there is no distinction between the tensile and compressive strengths [26]. The Tsai-Hill failure theory is written mathematically for the lamina as:

$\frac{\sigma_{1}^{2}}{\left(\sigma_{1}^{F}\right)^{2}}-\frac{\sigma_{1} \sigma_{2}}{\left(\sigma_{1}^{F}\right)^{2}}+\frac{\sigma_{2}^{2}}{\left(\sigma_{2}^{F}\right)^{2}}+\frac{\tau_{12}^{2}}{\left(\tau_{12}^{F}\right)^{2}} \leq 1$

where $\sigma_{1}^{F}$ and $\sigma_{2}^{F}$ are the stresses along the longitudinal and transverse directions of the fiber, $\tau_{12}^{F}$ is the shear stress developed by [26].

The Fringe plots of Tsai-Hill Failure for model 2 and model 4 at the end of the analysis, given in Figure (11) and Figure (12). The FE analysis predicts the central peak observed first at the centroid of the top surface of the front face also occurred at the middle of the sides of the plates and then progressed towards the corners according to [27 and 28].

Figure (13) shows the maximum Tsai-Hill Failure for model 2, model 3, model 4, model 5 and model 6. The maximum magnitude of Tsai-Hill Failure occurs at the last ply in the front face. The PVC foam core changes the mechanism of velocity transfer to the back face of the panel which causes a delay and significant reduction of the transverse velocity transmitted to the back sheet. It is due to the velocity attenuation caused by the compaction of the foam core so that The Tsai-Hill failure in the front face is higher than the Tsai-Hill failure in the back face for all models. It indicates that when the damage occurs, it propagates faster in the last ply in the front face where there are high tensile stresses developed. It reveals that as the core thickness decrease the maximum Tsai-Hill Failure increase which confirm that the proposal with maximum core thickness can help the structure to sustain shock loads resulting from an underwater explosion. 
For model 1,the equivalent plastic strain in a material (PEEQ) is calculated as an indicator to structural integrity which is a scalar variable that is used to represent the material's inelastic deformation. If this variable is greater than zero, the material is yielded [22].

Figure (13) shows a contour plot of accumulated PEEQ for model 1 and permanent deformations are monitored which emphasize that the largest permanent deformation is obtained on model 1. The FE analysis predicts the central peak observed and permanent deformations first occurred at the middle of the sides of the plates and then progressed towards the corners according to experimental results reported in [29, 30].

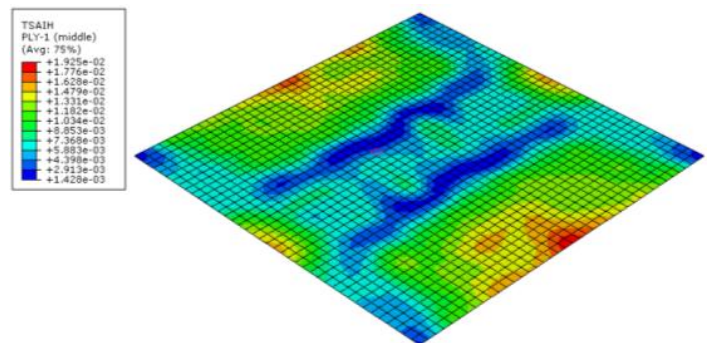

First Ply in front face

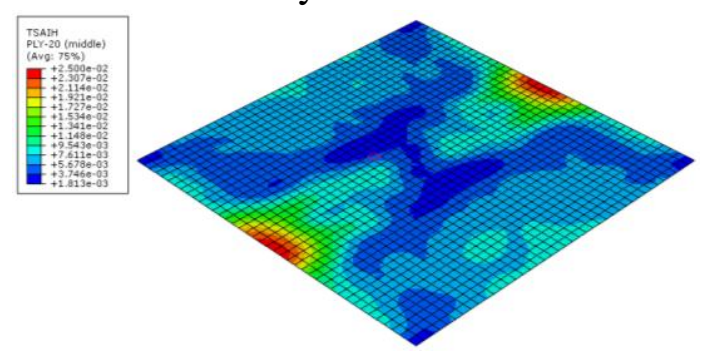

First Ply in back face

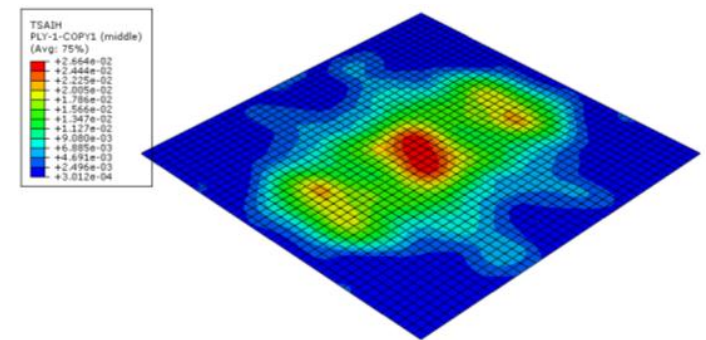

Last Ply in front face

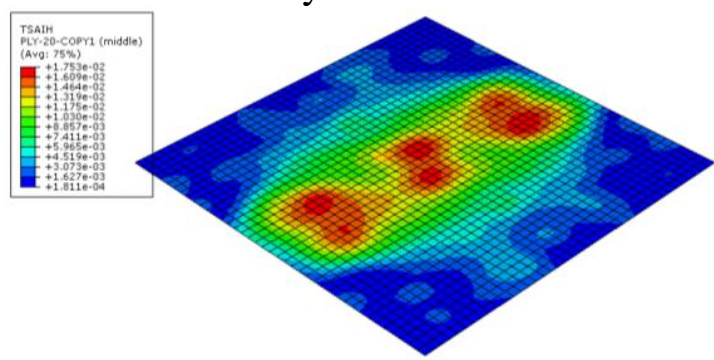

Last Ply in back face

Fig. 11. Tsai-Hill Failure distribution for model 2
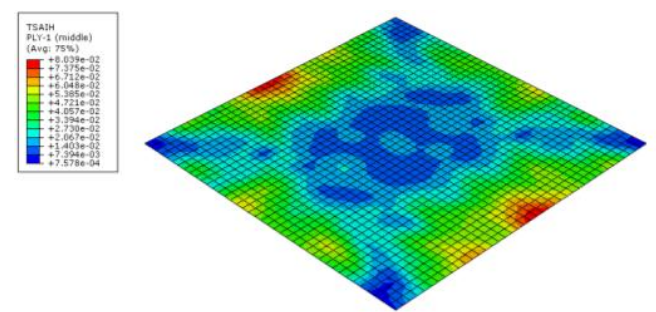

First Ply in front face
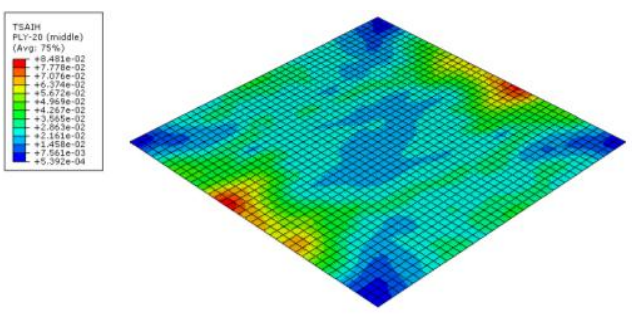

First Ply in back face

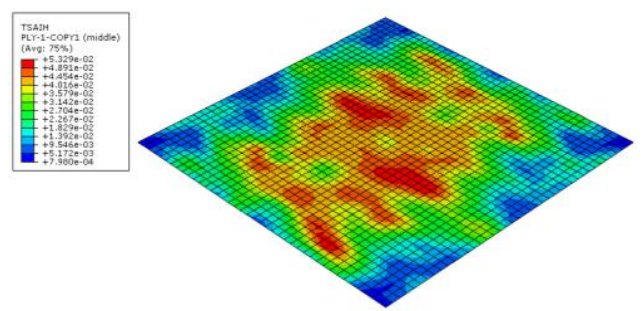

Last Ply in front face

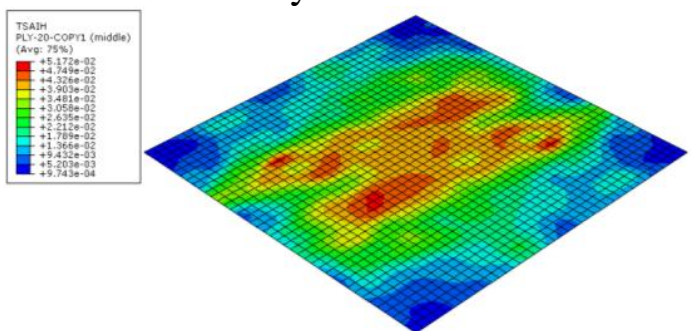

Last Ply in back face

Fig. 12. Tsai-Hill Failure distribution for model 4 


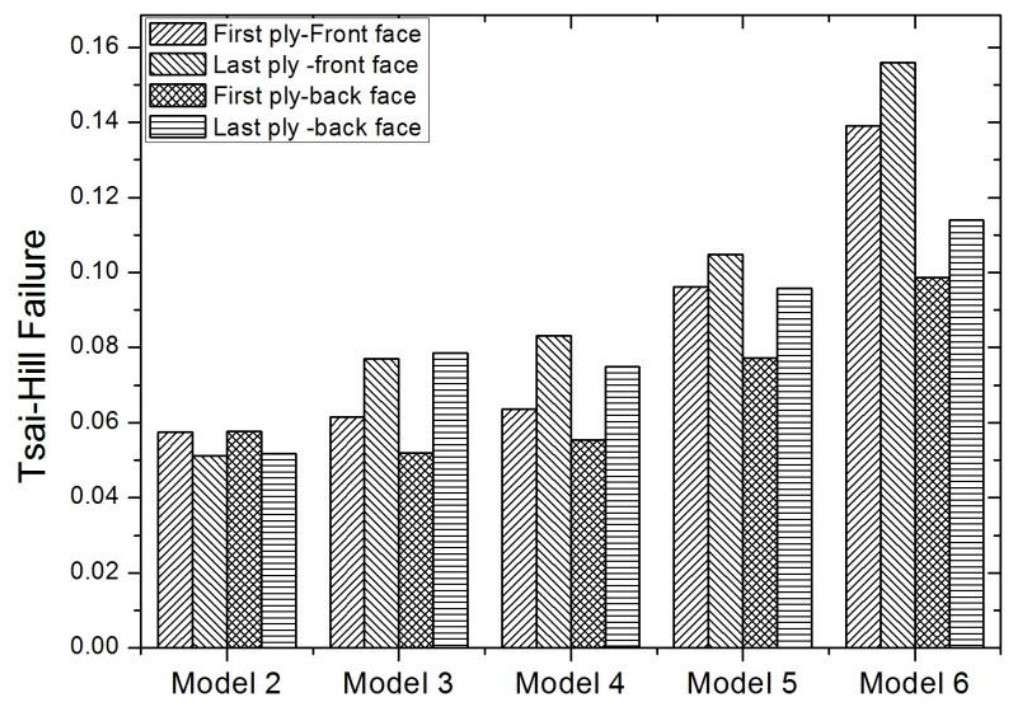

Fig. 13. The maximum Tsai-Hill Failure for all models

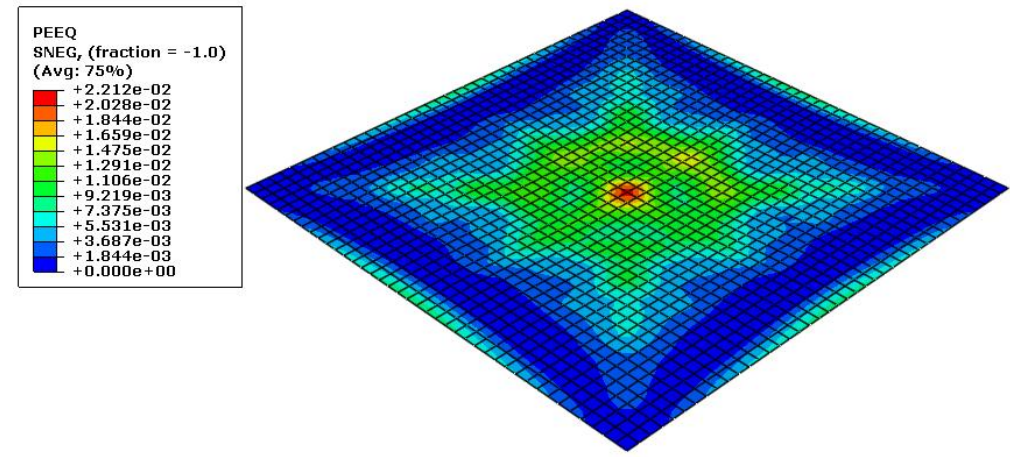

Figure 14: The accumulated equivalent plastic strain for model 1(PEEQ).

\section{Conclusions}

From the non-linear dynamic finite element analyses carried out to examine the behavior of composite panels subjected to underwater shock loading, it can be concluded that:

The displacement-time histories under shock loadings are presented which will be used in designing composite panels so as to enhance resistance to underwater shock damage. The effect of core thickness is very important, since it can affect drastically the overall behavior of the plates as indicated. The inclusion of core within the plate decreases the mid-point displacement significantly. Therefore, the core thickness has an important influence on the response of the plates. The results show that the Improvement Ratio $\left(I_{R}\right)$ for all models has been enhanced significantly. It can be noted that the best $\left(I_{R}\right)$ is $58.20 \%$ for model 2 and the lowest $\left(I_{R}\right)$ is $31.34 \%$ for model 6 which indicate that as the core thickness increase the Improvement Ratio increase improving the behavior response of the plates to the shock loading .

The Tsai-Hill failure in the front face is higher than The Tsai-Hill failure in the back face for all models, the central peak observed first at the centroid of the top surface of the front face also occurred at the middle of the sides of the plates and then progressed towards the corners, which indicate that when the damage occur it propagates faster in the last ply in the front face where there are high tensile stresses. 


\section{References}

[1] Z. Zong et al. A numerical study of whole ship structural damage resulting from closein underwater explosion shock. Marine Structures 31 (2013): 24-43

[2] Z. Wei et al. Analysis and interpretation of a test for characterizing the response of sandwich panels to water blast. International Journal of Impact Engineering 34 (2007) $1602-1618$

[3] Y. Chi et al.[2] The influence of core height and face plate thickness on the response of honeycomb sandwich panels subjected to blast loading. Materials and Design 31 (2010) 1887-1899

[4] Fleck NA, Deshpande VS. The resistance of clamped sandwich beams to shock loading. J Appl. Mech 2004;71:386-401.

[5] Yuen SCK, Nurick GN, Theobald MD, Langdon GS. Sandwich panels subjected to blast loading. In: Shukla A, Rajapakse Y, Ravichandran G, editors. Dynamic failure of materials and structures. Springer; 2009.

[6] H.E. Johnson et al. Modelling impact damage in marine composite panels International Journal of Impact Engineering 36 (2009) 25-39

[7] F. Latourte et al. Failure mechanisms in composite panels subjected to underwater impulsive loads. J. Mech. Phys. Solids 59 (2011) 1623-1646

[8] LeBlancJames, ShuklaArun. Dynamic response of curved composite panels to underwater explosive loading: experimental and computational comparisons. Composite Structures; 2011;93:3072-81.

[9] C.Y. Jen. Coupled acoustic-structural response of optimized ring-stiffened hull for scaled down submerged vehicle subject to underwater explosion. Theoretical and Applied Fracture Mechanics 52 (2009) 96-110.

[10] A. Forghani, C. McGregor, S. McClennan, R. Vaziri, F. Ellyin, A. Poursartip, A. Bouamoul. Modelling of damage development in blast loaded composite panels. The 16th International Conference on Composite Materials, Kyoto, 2007, pp. 1-8.

[11] RH. Cole . Underwater explosions. New York: Dover Publications Inc.; 1948.

[12] AH. Keil. The response of ships to underwater explosions. Trans Soc. Naval Archit Mar Eng. 1961;69:366-410.

[13] G.S. Langdon et al. The air-blast response of sandwich panels with composite face sheets and polymer foam cores: Experiments and predictions International Journal of Impact Engineering 54 (2013) 64-82.

[14] Tekalur SA, Shivakumar K, Shukla A. Mechanical behaviour and damage evolution Eglass vinyl ester and carbon composites subjected to static and blast loads. Compos Pt B 2008:57-65.

[15] AH. Keil. The response of ships to underwater explosions. Trans Soc. Naval Archit. Mar Eng. 1961;69:366-410.

[16] R. Kalavalapally. Multidisciplinary optimization of a lightweight torpedo structure subjected to an underwater explosion. Finite Elements in Analysis and Design 43 (2006) $103-111$

[17] K. Hibbitt, I. Sorensen. ABAQUS Theory Manual. Version 6.10, USA; 2010.

[18] AM. Zhanget. The interaction of an underwater explosion bubble and an elastic-plastic structure. Applied Ocean Research 30 (2008) 159-171.

[19] Y. S. Shin. Naval Ship Shock and Design Analysis. Course Notes for Underwater Shock Analysis, Naval Postgraduate School, Monterey, California, 2006.

[20] C.-Y. Jen, Y.-S. Tai Deformation behavior of a stiffened panel subjected to underwater shock loading using the non-linear finite element method / Materials and Design 31 (2010) 325-335. 
[21] K. Hibbitt, I. Sorensen. ABAQUS Example Problems Manual. Version 6.10, USA; 2010

[22] K. Hibbitt, I. Sorensen. ABAQUS Analysis User's Manual. Version 6.10, USA. 2010

[23] K. Hibbitt, I. Sorensen. ABAQUS Tutorial, Getting Started with ABAQUS, interactive Edition. Version 6.10, USA, 2010.

[24] B. Panahi et al. Transient response of a submerged cylindrical foam core sandwich panel subjected to shock loading/ Materials and Design 32 (2011) 2611-2620

[25] J.Y Zheng, P.F. Liu Elasto-plastic stress analysis and burst strength evaluation of Alcarbon fiber/epoxy composite cylindrical laminates

[26] George Z. Voyiadjis Peter I. Kattan. Mechanics of Composite Materials with MATLAB. ISBN-10 3-540-24353-4 Springer Berlin Heidelberg New York

[27] G.S. Langdon et al. The air-blast response of sandwich panels with composite face sheets and polymer foam cores: Experiments and predictions. International Journal of Impact Engineering 54 (2013) 64e82

[28] R.C. Batra, N.M. Hassan. Response of fiber reinforced composites to underwater explosive loads. Composites: Part B 38 (2007) 448-468

[29] S. Chung Kim Yuen, G.N. Nurick. Experimental and numerical studies on the response of quadrangular stiffened plates. Part I: subjected to uniform blast load International Journal of Impact Engineering 31 (2005) 55-83

[30] G.S. Langdon et al. Experimental and numerical studies on the response of quadrangular stiffened plates. Part II: localized blast loading International Journal of Impact Engineering 31 (2005) 85-111 